\title{
Management of environmental streaming data to optimize Arctic shipping routes
}

\author{
Zhihua Zhang $^{1,2} \cdot$ M. James C. Crabbe ${ }^{3,4,5}$ \\ Received: 22 April 2021 / Accepted: 26 June 2021 / Published online: 20 July 2021 \\ (C) The Author(s) 2021
}

\begin{abstract}
Dynamic accurate predictions of Arctic sea ice, ocean, atmosphere, and ecosystem are necessary for safe and efficient Arctic maritime transportation; however a related technical roadmap has not yet been established. In this paper, we propose a management system for trans-Arctic maritime transportation supported by near real-time streaming data from air-space-ground-sea integrated monitoring networks and high spatio-temporal sea ice modeling. As the core algorithm of integrated monitoring networks, a long short-term memory (LSTM) neural network is embedded to improve Arctic sea ice mapping algorithms. Since the LSTM is localized in time and space, it can make full use of streaming data characteristics. The sea ice-related parameters from satellite remote sensing raw data are used as the input of the LSTM, while streaming data from shipborne radar networks and/or buoy measurements are used as training datasets to enhance the accuracy and resolution of environmental streaming data from outputs of LSTM. Due to large size of streaming data, the proposed management system of trans-Arctic shipping should be built on a cloud distribution platform using existing wireless communications networks among vessels and ports. Our management system will be used by the ongoing European Commission Horizon 2020 Programme "ePIcenter."
\end{abstract}

Keywords Arctic climate change $\cdot$ Arctic routes $\cdot$ Streaming data $\cdot$ Management system of trans-Arctic shipping

\section{Introduction}

The dramatic shrinking and thinning of the summertime area of Arctic sea ice over the preceding 4 decades, especially in autumn and summer, accelerates deployments of large-scale trans-Arctic maritime transportation in the near future. The shipping industry has become increasingly interested in

\section{Responsible Editor: Amjad Kallel}

M. James C. Crabbe

james.crabbe@wolfson.ox.ac.uk

Zhihua Zhang

zhangzhihua@sdu.edu.cn

1 Climate Modeling Laboratory, School of Mathematics, Shandong University, Jinan 250100, China

2 MOE Key Laboratory of Environmental Change and Natural Disaster, Beijing Normal University, Beijing 100875, China

3 Wolfson College, Oxford University, Oxford OX2 6UD, UK

4 School of Life Sciences, Shanxi University, Taiyuan 030006, China

5 Institute of Biomedical and Environmental Science \& Technology, University of Bedfordshire, Park Square, Luton LU1 3JU, UK
Arctic shipping due to lower shipping costs, reduced carbon emissions, and shorter voyage times when Arctic routes are compared with the traditional Asia-Europe Suez Canal Route (Fu et al. 2021). Main Arctic shipping routes include the Arctic northeast passage along the Russian Siberian coast, the Arctic northwest passage through the Canadian Arctic Archipelago, and the Arctic pole route (Giguère et al. 2017). Among these three routes, the most feasible is the Arctic northeast passage, since more sea ice has retreated and will continue to retreat near the Russian Siberian coast than in other parts of Arctic Ocean (Zhang et al. 2016). In practice, since 2000 , the number and size of vessels navigating through the Arctic northeast passage has been much high than through the other two routes. Seventy-one vessels passed through the Arctic northeast passage in 2013, while the first vessel passed through the Arctic northwest passage in 2014. The Arctic pole route is not accessible in the near future. Compared with the routes via the Suez Canal or the Cape of Good Hope, the relatively mature Arctic northeast routes along the Siberian coast can reduce the navigational distances between East Asia and Europe ports by $25-43 \%$ (Aksenov et al. 2017). At the same time, increasing Arctic shipping activities will harm the Arctic ecosystem, especially given that the negative effects 
of carbon and pollutant emissions in the Arctic routes would outweigh the advantage of shorter distance (Østreng 2015). Under the business-as-usual scenario, the overall shipping carbon emission on the Arctic northeast passage by 2050 will be 1.76 times the emission level in 2020. Jing et al. (2021) suggested that switching to cleaner fuels (such as LNG) and slow steaming are effective ways of emission reduction.

Yearly variations in Arctic sea ice distribution and thickness will still threaten the safety of vessel navigation along Arctic routes. Potential risks depend on intra-annual spatial variability and sudden changes in sea ice conditions in the Arctic. The Arctic severe weather (e.g., the strong winds, snow storms, reduced visibility in fog) and the remoteness from navigation support services (e.g., navigational, hydrographic, meteorological, communication, emergency rescue, vessel waste disposal) also increase navigational threats (Gavrilov et al. 2019). Dynamic accurate predictions of Arctic sea ice, ocean, atmosphere, and ecosystem are necessary for safe and efficient Arctic maritime transportation (Aksenov et al. 2017). However the core management system for the whole Arctic shipping to balance between risks and costs has not been effectively studied; only Zhang et al. (2019) have given a framework for a big data-driven dynamic optimal trans-Arctic route (DOTAR) system. Although the DOTAR system is designed to use big environmental data as its input, the core algorithm in the DOTAR system is still based on traditional data assimilation algorithms, and no deep learning techniques are embedded. Moreover, the DATOR system does not make use of streaming data characteristics for Arctic big data and does not show how to mine useful information from streaming data using shipborne radar systems and buoy measurements into the DOTAR system. In this paper, we overcome the disadvantages of the DOTAR system and establish a management system of environmental streaming data from a near real-time air-space-ground-sea integrated environmental monitoring network and high spatio-temporal sea ice modeling to support trans-Arctic maritime transportation. The management system can help to adjust and optimize shipping routes in near real time in order to maintain safe distances from large-size ice floes and to save time, fuel, and costs and to minimize risks. Our management system will be used by the ongoing European Commission Horizon 2020 Programme "Enhanced Physical Internet-Compatible EarthfrieNdly freight Transportation answer (ePIcenter)" as a core part of a trans-Arctic transportation system.

\section{Streaming data from Arctic remote sensing measurements}

More than 10 million $\mathrm{km}^{2}$ of sea ice melt and re-form every year. Seasonal melt-freeze transitions over sea ice are closely linked with Arctic sea ice extent and thickness, and this has large impacts on the uncertainty of trans-Arctic shipping seasons. Streaming data from near real-time and spatially extensive sea ice observations are important for managing Arctic navigation routes. Since the high reflective nature of snow/ice presents a good contrast with open water and other natural surface covers, streaming data from satellite remote sensing is a low-cost tool for monitoring changes of Arctic sea ice extent and thickness. Since satellite microwave remote sensing is not affected by solar illumination and clouds, it is the most reliable and accurate approach to monitor changes of Arctic sea ice conditions. Satellite microwave remote sensing can be divided into passive microwave remote sensing and active microwave remote sensing.

Satellite passive microwave sensor measurements can provide basin-scale observations at a spatial resolution of $12.5 \mathrm{~km}$ or $25 \mathrm{~km}$. Known passive microwave sensors include the Scanning Multi-Channel Microwave Radiometer (SMMR) on NASA's Nimbus-7 satellite, the Special Sensor Microwave Imager (SSM/I) or Sounders (SSMIS) on DOD/ DMSP satellites, and the Advanced Microwave Scanning Radiometer-Earth Observing System (AMSR-E and AMSR2) on NASA EOS Aqua and GCOM-W1 satellites. Due to significant differences in brightness, temperature at different frequencies, and polarizations between open waters and ice, the daily temporal resolution of passive microwave brightness temperatures provides the most widely utilized observations to retrieve Arctic sea ice conditions but is limited to coarse spatial resolution. The latest AMSR2, placed on-orbit in 2012, offers a significant improvement in spatial resolution, especially at $89 \mathrm{GHz}$, of approximately $3 \times 5 \mathrm{~km}^{2}$. The swath width of AMSR2 is $1450 \mathrm{~km}$, leading to relatively high temporal resolution (Chi et al. 2019). Two mainstream sea ice concentration retrieval algorithms to utilize streaming data from passive microwave sensors are as follows: The NASA sea ice algorithm is based on the difference of the polarization and spectral gradient ratios of sea ice and open water (Cavalieri et al. 1996); the bootstrap algorithm is based on interpolation of brightness temperatures in consolidated ice regions and ice-free regions (Cho and Naoki 2015). Under sky conditions without cloud-atmosphere aerosol contamination, low-resolution streaming data from passive microwave sensors can be enhanced further by high-resolution streaming data from the MODerate-resolution Imaging Spectroradiometer (MODIS) instruments on NASA EOS Terra and Aqua satellites. During summertime, the surface of the Arctic ice can vary from deep snow to bare ice to melt ponds ( $\mathrm{Lu}$ et al. 2017). At present, the existence of melt ponds over Arctic sea ice is still a big challenge for Arctic sea ice remote sensing since they have large spatio-temporal variability and have features similar to open water. Generally, the depth of melt ponds is $<50 \mathrm{~cm}$ on first-year ice and $<70 \mathrm{~cm}$ on multiyear ice. The smaller albedo of melt ponds compared with sea ice often leads to further melting and then change ice 
conditions (Lu et al. 2016). Misjudgment of melting ponds as open water possibly misguides vessels to sail into dangerous regions. One solution is to use streaming data from optical remote sensing (e.g., MODIS data) to obtain melting pond fractions in certain Arctic regions.

As an active microwave remote sensing, synthetic aperture radar (SAR) has high spatial resolution (50-100 m) with low spatial coverage and temporal resolution and is also independent of sunlight and clouds. Known SAR satellites include the German Aerospace Center's X-band TerraSAR-X, the Canadian Space Agency's C-band Radarsat-2, the European Space Agency's C-band Sentinel, and Japan's Advanced Land Observing Satellite-2 with onboard L-band SAR (PALSAR-2). Generally, C-band SAR is more sensitive to sea ice with thickness $<0.12 \mathrm{~m}$, and L-/X-band SAR is more sensitive to sea ice thickness $>0.12 \mathrm{~m}$. Due to high spatial resolution, streaming data from the combination of $\mathrm{X}-\mathrm{C}$-, and L-band SAR satellites make it possible to provide automatic detailed information of concentration, extent, and drift patterns of icebergs or large-scale ice floes, particularly regarding lead and floe size distribution (Johansson et al. 2018). The drift patterns of iceberg and large-scale ice floes can be detected by using cross- and phase correlation techniques to register ice features from satellite SAR data over different acquisition times and then calculate the moving distance of sea ice. More advanced techniques are entropy-based multi-scale matching and optical flow techniques (Du et al. 2019). Generally, L-band SAR can detect higher confidence sea ice motion vectors during melt and freeze-up, while Cband ice motion is more spatially representative than L-band SAR over dry multi-year ice (Howell et al. 2018). Due to narrow swath width, one satellite with onboard SAR often spends 15-30 days to map sea ice conditions along the whole Arctic routes. Although the spatial coverage of combined all SAR satellites is increasing, there are still a big gap in spatial and temporal scales across the Arctic routes.

Different from passive microwave sensors and SARs, scatterometers are active microwave remote sensors offering a balance between spatial resolution and coverage in Arctic regions. They can provide information on snow-ice-ocean interactions of the Arctic region each day at $4.45 \mathrm{~km}$ resolution via resolution-enhanced algorithms (Mortin et al. 2014). The known C-band instrument Advanced Scatterometer (ASCAT) is onboard three polar orbiting satellites of European Space Agency (ESA). Streaming data from scatterometers cannot be used to estimate sea ice concentration directly, but it can assess sea ice extent/cover by performing discrimination analysis at relatively high resolution.

The thickness of Arctic sea ice can pose notable impacts on icebreaking costs, operating costs, and depreciation costs of vessels shipping along Arctic routes. A non-ice-strengthened vessel in Arctic sea ice-prone regions could incur catastrophic damages. Assuming that sea ice is in hydrostatic equilibrium, various altimetry onboard high-latitude satellites can retrieve sea ice thickness from the freeboard height (the height of sea ice surface relative to local sea level). The Cryosat- 2 has a profiling radar altimeter (Ku-band) that can penetrate snow on sea ice and measure the sea ice elevation above a reference ellipsoid, so it can reveal inter-annual fluctuations of Arctic sea ice thickness. Cryosat-2's radar altimeter operates in three modes: low-resolution mode, high-resolution SAR mode, and SAR interferometric model. CryoSat-2 sea ice thickness estimates have been shown to agree with those from airborne and ocean-based platforms to within $2 \mathrm{~mm}$, on average, which is much smaller than the accuracy of either dataset $(10-40 \mathrm{~cm})$ (Tilling et al. 2018). The main contributors to the uncertainty in sea ice thickness retrieval are the depth and density of snow existing on the ice cover and the densities of ice and seawater. One solution is to use the combination of SARAL-AltiKa and CryoSat- 2 altimeters at $\mathrm{Ka}$ - and $\mathrm{Ku}$-band frequencies to retrieve snow depth with an accuracy better than $3 \mathrm{~cm}$ (Guerreiro et al. 2016). The Sentinel-3A and Sentinel-3B satellites carrying a dual frequency ( $\mathrm{Ku}$ and $\mathrm{C}$ band) SAR Radar altimeter were launched in 2016 and 2018, respectively. Compared with CryoSat-2 alone, the use of the combination of CryoSat-2 and two Sentinel satellites in Arctic sea ice thickness estimates can enhance the spatial resolution from $15(25)(50)$ to $5(10)(15) \mathrm{km}^{2}$ and the temporal resolution from 30 days to 10 days and reduce the uncertainty by a quarter on average (Lawrence et al. 2021). Satellite data has revealed that the trend for thick multiyear winter sea ice area is a loss of $17.2 \%$ per decade since 1979 , and the mean thickness during the 2000s was around $2 \mathrm{~m}$ (Langehaug et al. 2013).

Satellite monitoring of marginal ice zones with newly formed open water or ice plays a key role in searching for cost-effective shipping passages through the ice. In order to maintain safe distances from icebergs and large-size ice floes and to save time, fuel, and costs, satellite remote sensing needs to monitor the whole Arctic region (especially marginal ice zones) in a near real-time manner; i.e., the temporal resolution needs to be increased from days into hours. At present, steaming data flow from existing satellite remote sensing is not enough to support blooming trans-Arctic shipping in the near future. Two solutions are proposed: One is to use the combination of polar synchronous satellites. The Canadian RADARSAT Constellation Mission launched in June 2019 consists of three C-band SAR satellites as well as an associated ground segment. Although the spatial resolution reaches meter scale, streaming data from RADARSAT satellites still cannot achieve the aim of hourly monitoring of Arctic ice conditions due to low temporal resolution. At the same time, the European Space Agency is developing the Sentinel satellite constellation, where each mission is based on a constellation of two satellites. Due to the high economic cost of complex polar synchronous satellites, it is difficult to use multisatellite constellations and then achieve the aim of near real- 
time monitoring of Arctic routes. The other solution is a socalled low-cost nanosatellite constellation model, which emphasizes simplicity in design, minimal cost, and disposability and replacement, making possible the use of multi-satellite constellations to support Arctic shipping. The Dove satellite constellation of Planet Labs has made up the world's largest constellation; this can be expected to monitor sea ice conditions along Arctic routes. The Chinese government is planning to construct and launch a triple-pole constellation equipped with 24 micro/nano satellites. The first experimental satellite Ice Pathfinder with a resolution of $80 \mathrm{~m}$ was launched in September 2019. It can cover the whole Arctic region every 5 days. Onboarded AIS receivers can be used to test communications between satellites and vessels/ports. The whole constellation of 24 micro/nano satellites will be expected on-orbit before 2030 .

\section{Streaming data from buoy and airborne measurements}

Any piece of floating sea ice with a size $>20 \mathrm{~m}$ is called an ice floe (Kwok 2014). The drift pattern of small-scale sea ice floes is very difficult to monitor by satellite remote sensing or predict by sea ice models or fully coupled climate models, but they seriously threaten navigation safety along Arctic routes. Due to the extreme climate and environment conditions in high latitudes, in situ measurements of sea ice concentration, extent, and thickness are spatially and temporally sparse in Arctic regions. As the only low-cost reliable in situ measurements, buoys can track drifting sea ice floes with $1 \mathrm{~m}$ resolution.

The International Arctic Buoy Program (IABP), initiated by the Polar Science Center, is a network of drifting buoys in the Arctic Ocean to provide meteorological and oceanographic data. Its main aim is to develop a comprehensive and sustainable Arctic observational network and produce streaming data used as validation of satellite remote sensing data and forcing/validation/assimilation climate models. The main types of ice buoys used in the Arctic Ocean are Sea Ice Mass balance buoys, Ice Surface Velocity Program buoys, and Snow and Ice Mass Balance Array buoys. These buoys can record position, air temperature and pressure, snow and ice temperature, and ice concentration and thickness (Lei et al. 2020). Streaming data from these buoys can successfully integrate into global wireless communication systems according to the IABP protocols.

Except for monitoring sea ice concentration, extent, and thickness, suitable buoys can also help to obtain key physical and thermodynamic features of ice floes along Arctic navigation routes, which cannot be achieved by satellite remote sensing or sea ice modeling. Along the Arctic routes, when ice interacts with the hull of a vessel, it may rotate and collide with the vessel or slide along the vessel's hull. Related physical and thermodynamic features, such as tensile strength, flexural strength, failure envelope, and uniaxial compression strength of Arctic sea ice, can affect icebreaking and operational and depreciation costs (Wang et al. 2018a). At the same time, the weakness of Arctic ice strength will significantly accelerate sea ice drift and increase ice deformation. It is clear that physical and thermodynamic features of ice floes detected by buoys are important for safe Arctic shipping.

Estimates of Arctic sea ice extent and thickness can also acquire from airborne observations, such as the NASA Operation IceBridge, where a frequency-modulated continuous-wave radar, a digital camera, and a laser scanner system are mounted on a fixed-wing aircraft. Generally, the airborne radar measurements always underestimate snow depths on sea ice because of radar range resolution and rough ice surfaces. The bias of snow depth estimates from airborne measurement is often larger than $20 \mathrm{~cm}$ (K. Castro-Morales et al. 2017). Since the cost of airborne measurements are higher than buoy measurements or satellite remote sensing measurements, airborne measurements only work for several weeks a year, and it is only viewed as an auxiliary tool to support Arctic shipping.

\section{Streaming data from shipborne radar systems}

Shipborne radar systems on vessels can provide high-resolution, continuous, and accurate monitoring of sea ice conditions along Arctic routes, especially recording of small-scale ice features that are undetectable by satellites. The detecting distance and accuracy of Arctic sea ice is closely linked with the capability of shipborne radar, the height of antennae, and the sea ice surface characters. However, shipborne radar systems are ignored by current researches on Arctic maritime transportation. When the summer Arctic Ocean become nearly ice free in the next 3 decades, the number of vessels shipping along Arctic routes will increase significantly; furthermore, the size and the spatio-temporal resolution of streaming data from the network of shipborne radars are rapidly increasing, which make these streaming data important for real-time monitoring sea ice conditions and weather and environmental conditions along Arctic routes. More importantly, since at present streaming data from shipborne radar networks have been widely used in traditional navigation and distributed using existing wireless communication systems between vessels or between vessels and ports, the acquisition of streaming data from shipborne radar network will not bring additional costs for shipping companies. Noticing that the resolution is better than remote sensing measurement, these streaming data have great potential to replace streaming data from high-cost buoy and airborne measurement systems in the short-term and remote sensing measures in the long term, in order to guarantee safe and efficient trans-Arctic navigation through iceinfested waters and to significantly reduce the cost of Arctic 
sea ice monitoring. When vessels ship along the Arctic routes, vessel hulls interact directly with sea ice, so physical and thermodynamic properties of sea ice along Arctic routes can also be measured by suitable sensors onboard vessels (e.g., downward-oriented and oblique-oriented cameras). In addition, since short distances between vessels lead to the risk of collisions while long distances will increase icebreaking costs and related depreciation cost of vessels, sea ice conditions observed by shipborne radar networks can help to determine optimal distances between vessels.

\section{Streaming data from Arctic sea ice predictions}

The spatial sea ice extent in the Arctic has declined at a rate of $14 \%$ per decade since the beginning of the satellite record in 1979 (Mahmud et al. 2016; Stroeve et al. 2014). Arctic sea ice is gradually transiting from a thick multi-year ice regime to a thin first-year ice regime. The Arctic is estimated to lose over $60 \%$ in annual mean sea ice thickness (Lindsay and Schweiger 2015). Accurate sea ice modeling and predictions depend heavily on sea ice initial states and atmospheric/oceanic forcing (Yang et al. 2019); e.g., cyclones entering the Arctic Ocean contribute to drift patterns of ice floes and the redistribution of sea ice; ocean heat transport from North Atlantic currents also significantly impacts sea ice extent and thickness. At the same time, the snow scheme in most models is still a single layer of snow with oversimplification representation of density, grain size, and thermal conductivities of snow over the entire Arctic (Castro-Morales et al. 2017). Arctic sea ice predictions have revealed that a later freeze-up contributes more than earlier break-up to the overall shortening of annual sea ice duration in the near future (Wang et al. 2018b). At the current rate of sea ice retreat, all long-term predictions from Arctic modeling reveal that the current declining trends in sea ice extent will not abate and the Arctic Ocean will become nearly ice free in one summer during 2030-2050. However, the streaming data from these long-term predictions can only be used to assess future patterns of Arctic shipping change and support potential transportation strategies and related investment from littoral Arctic countries and cannot be used directly to plan/adjust/manage annual Arctic shipping routes to achieve low-cost and low-risk aims.

Short-term predictions (i.e., seasonal scale or yearly scale) of Arctic sea ice conditions by sea ice models or fully coupled climate models can lead to good estimates of the length of navigation seasons for the Arctic shipping passages. The much-needed high-resolution initial sea ice states, which are provided by increasing streaming data from satellite remote sensing measurements and in situ measurements, play a key role in producing realistic sea ice changes in the subsequent summer. Compared with historical observation data, both stand-alone and coupled climate models can successfully replicate observed patterns in the seasonal cycle of sea ice growth and melt (Yang et al. 2019) and can simulate Arctic sea ice break-up dates and freeze-up dates (Wang et al. 2018a). The streaming data from seasonal/yearly scale predictions can help shipping companies to make a suitable development plan at least one or two seasons ahead. At present, the season-scale (one or two seasons ahead) prediction of high spatio-temporal resolution Arctic sea ice condition still remains challenging with large uncertainties since the associated processes and mechanisms are complex and not yet fully understood. Enhanced understanding of sea ice dynamic and thermodynamic processes can help substantial improvement of parameterization schemes of Arctic sea ice and snow over sea ice (Kang et al. 2014). Since sea ice thickness initialization has more long-term impacts than that of sea ice concentration initialization on seasonal sea ice prediction, the latest Sea Ice Seasonal Prediction System (SISPS) is based on the MITgcm sea ice-ocean model and uses sea ice thickness assimilation data in its initial conditions (Yang et al. 2019).

Not only are seasonal predictions important for shipping time windows before the coming summers, the near real-time and synoptic scale sea ice predictions are also necessary during shipping in the Arctic (Yang et al. 2019). Steaming data from synoptic scale prediction can help vessels to ship in the most cost-effective route and minimize the risks from iceberg and large-scale ice floes. The accuracy of the near real-time and synoptic scale predictions on sea ice is high since the bias can be corrected largely by assimilation with observational data from various sources.

\section{Steaming data-based management systems for trans-Arctic routes}

The management of Arctic navigation routes should be established on near real-time streaming data from air-spaceground-sea integrated monitoring networks on Arctic sea ice concentration, thickness, and drift patterns at high spatiotemporal resolution.

Main in situ measurements consist of a shipborne radar network, a buoy network, and a shore-based radar network. The use of a shipborne radar network and a shore-based radar network is proposed initially. Although these two in situ measurements are always ignored by existing researches on Arctic shipping, with the increase in Arctic shipping and the improvement of infrastructure along Arctic routes, a low-cost shipborne radar network and a shore-based radar network should replace the buoy network in the near future. Due to the remoteness from navigation support services, in situ measurements of sea ice along the Arctic northeast passage, we suggest using a combination of a buoy network and a shipborne radar network. Since the existence of the Canadian Arctic Archipelago leads to narrow water channels, the 
combination of shore-based radar network and shipborne radar network is suggested to use as in situ measurements along the Arctic northwest passage. Due to high cost, limited airborne observations are suggested to use as an auxiliary tool to fill the gap among buoy network, shipborne radar network, and shore-based radar network.

Satellite-borne passive microwave sensor measurements can provide observations at coarse spatial resolution and relatively high temporal resolution, while SAR satellite can provide observations at finer spatial resolution and low temporal resolution, so the remote sensing retrieval products on sea ice conditions from existing on-orbit satellite observations cannot support blooming exploitation of Arctic routes. This will be improved gradually by launching various micro/nano satellite constellations. At present, all known Arctic sea ice remote sensing data are calibrated by limited outdated in situ measurements; e.g., snow on Arctic sea ice, a key parameter in estimates of ice thickness, is poorly monitored; all existing studies are based on a past climatology of snow depth from Warren et al. (1999) although a significant warming has occurred in the past 20 years. Moreover, these data products and related remote sensing retrieval algorithms cannot be updated automatically by incorporating new in situ measurements. The use of traditional data assimilation techniques is just to minimize some bias between satellite sea ice retrieval data and in situ measurements under simple statistical assumptions. Therefore, we present an innovative sea ice mapping algorithm (see Figure 1): The deep learning model used is the long short-term memory (LSTM) neural network which can successfully solve vanishing or exploding gradient problems in estimates of the interneuron connection strengths (i.e., synaptic weights). The LSTMs replace the neurons in neural networks with cells whose input/output/forget gates have a special memory ability to retain useful information and remove extraneous data, so the LSTMs are localized in time and space and then can make full use of streaming data characteristics. The feature parameters (e.g., brightness temperatures, polarization, and spectral gradient ratios) from satellite remote sensing raw data, which are closely related to sea ice, can be used as the inputs of the LSTM model. The high spatiotemporal resolution shipborne radar measurements, buoy measurements, and shore-based radar measurements are used as training datasets. When there is a large bias between sea ice mapping data and in situ measurement data, the LSTM model needs to be trained again by new in situ measurement data, and related synaptic weights in the LSTM model will be updated. Compared with widely used empirical remote sensing retrieval algorithms and statistical data assimilation techniques, our sea ice mapping algorithm can make full use of unknown information hidden in remote sensing observations without accurately extracting/understanding the nonlinear and non-stationary observation process of satellite sensors on sea ice. After training with in situ measurements, the use of deep learning techniques can incorporate a collection of multisensor observations onboard different satellites and then enable enhanced accurate mapping of Arctic sea ice conditions at high spatio-temporal resolution. Since our sea ice mapping algorithm is based on the nonlinear and non-stationary remote sensing process and can be updated automatically according new in situ measurement data, our algorithm has a clear advantage over traditional algorithms (remote sensing retrieval + data assimilation) embedded DOTAR system. The combination of our deep learning-based sea ice mapping algorithm and existing wireless communication network can support

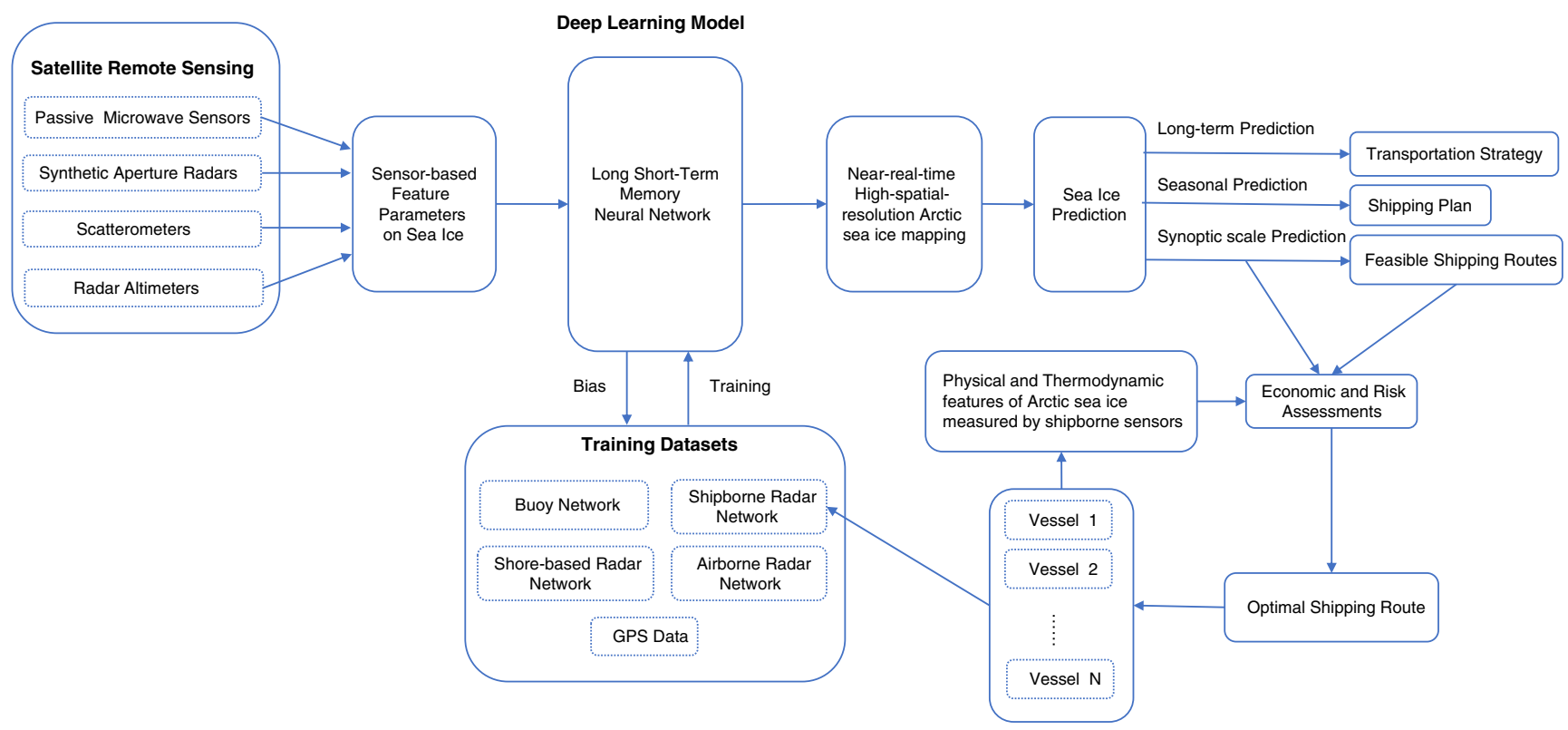

Fig. 1 Management of environmental steaming data to optimize Arctic routes 
the establishment of a near real-time air-space-ground-sea integrated monitoring network for Arctic routes.

By using streaming data from near real-time air-spaceground-sea integrated monitoring networks as the input (i.e., initial state) of sea ice models or full-coupled climate models, we can make long-term, short-term and synoptic scale sea ice predictions. All of these predictions can be updated automatically by inputting new sea ice mapping data (Figure 1). Longterm predictions will be used to support potential Arctic shipping strategies and investment from littoral Arctic countries. Short-term (seasonal/yearly scale) predictions can be used directly to plan Arctic shipping in the coming summer. The most important synoptic scale sea ice predictions can support near real-time dynamic optimal trans-Arctic routes (Figure 1). In detail, feasible shipping routes can be extracted easily according to synoptic scale predictions on sea ice concentration/ thickness, drift patterns, and vessel ice-strength class. Economic and risk assessment of these routes reveals the optimal shipping route by minimizing economic cost and possible damage loss. At present, economic and risk assessment is still immature and is based on limited empirical links between ice concentration/thickness and vessel ice-strength class. It is important to use buoy and shipborne sensors to accurately measure physical and thermodynamic properties, such as tensile strength, flexural strength, failure envelope, and uniaxial compression strength of Arctic sea ice along Arctic routes. Although these physical and thermodynamic properties can affect icebreaking and operational and depreciation cost when vessels ship along Arctic routes, existing researches ignore these key properties of sea ice. Accuracy economic and risk assessment in the near future must take these physical and thermodynamic properties into consideration (Figure 1).

\section{Discussion and conclusions}

Sea ice conditions of Arctic routes significantly affect navigational safety, economic costs, and navigable periods of transArctic transportation. Compared with the routes via the Suez Canal or the Cape of Good Hope, the Arctic routes can reduce the navigational distances between East Asia and Europe ports. Except for that, the exploitation of resources development (e.g., Yamal oil/gas field) and shipment of raw materials along the Arctic coast will also be a driver for the increase of trans-Arctic maritime transportation. Trans-Arctic shipping has been incorporated into the China national strategy "Ice silk road." Due to Arctic amplification of global warming, the increasing length and variability of the open water season is accelerating Arctic maritime transportation. However, increasing Arctic shipping activities must be balanced with any harm to the Arctic ecosystem, through pollution and greenhouse gas emissions, and it is important that ships become carbon-neutral at the earliest opportunity.
Environmental streaming data from near real-time airspace-ground-sea integrated monitoring networks and fullcoupled climate models will be necessary to support selection, evaluation, and economic analysis of Arctic commercial shipping routes. In this paper, we design a management system of environmental streaming data from air-space-ground-sea integrated monitoring networks and high-resolution sea ice predictions to optimize trans-Arctic maritime transportation. As the core algorithm of the integrated monitoring network, we have developed a LSTM-based sea ice mapping algorithm to replace traditional remote sensing sea ice retrieval algorithms and data assimilation techniques. LSTMs are local in time and space and can make full use of streaming data characteristics. The feature parameters (e.g., brightness temperatures, polarization, and spectral gradient ratios) from satellite remote sensing raw data, which is closed related to sea ice, can be used as the input of the LSTM model. The high spatio-temporal resolution shipborne radar measurements, buoy measurements, and shore-based radar measurements are used as training datasets. The main advantage of our algorithm lies in that it can make full use of unknown information hidden in environmental streaming data from remote sensing observations without accurately extracting/understanding the nonlinear and non-stationary observation process of satellite sensors on sea ice, while traditional remote sensing sea ice retrieval algorithms and data assimilation techniques are just based on simple statistical bias estimates. In addition, we also suggest incorporation of shipborne-sensors-measured physical and thermodynamic features of Arctic sea ice into accurate economic and risk assessments of Arctic routes. Due to the large size of streaming data, the proposed management of dynamic environmental streaming data should be built on a cloud distribution platform using wireless communications networks between vessels and ports. Our management system will be adopted by the ongoing European Commission Horizon 2020 Programme "Enhanced Physical Internet-Compatible Earth-frieNdly freight Transportation answer (ePIcenter)" as a core part of a trans-Arctic transportation system.

Funding This research was partially supported by the European Commission Horizon 2020 Programme "ePIcenter" and Taishan Distinguished Professorship Fund.

\section{Declarations}

Conflict of interest The authors declare that they have no competing interests.

Open Access This article is licensed under a Creative Commons Attribution 4.0 International License, which permits use, sharing, adaptation, distribution and reproduction in any medium or format, as long as you give appropriate credit to the original author(s) and the source, provide a link to the Creative Commons licence, and indicate if changes were made. The images or other third party material in this article are included 
in the article's Creative Commons licence, unless indicated otherwise in a credit line to the material. If material is not included in the article's Creative Commons licence and your intended use is not permitted by statutory regulation or exceeds the permitted use, you will need to obtain permission directly from the copyright holder. To view a copy of this licence, visit http://creativecommons.org/licenses/by/4.0/.

\section{References}

Aksenov Y, Popova EE, Yool A, Nurser AJG, Williams TD, Bertino L, Bergh J (2017) On the future navigability of Arctic sea routes: High-resolution projections of the Arctic Ocean and sea ice. Mar Policy 75:300-317

Castro-Morales K, Ricker R, Gerdes R (2017) Regional distribution and variability of model-simulated Arctic snow on sea ice. Polar Sci 13: 33-49

Cavalieri DJ, Parkinson CL, Zwally PGHJ (1996) Sea Ice Concentrations from Nimbus-7 SMMR and DMSP SSM/I-SSMIS Passive Microwave Data. NASA National Snow and Ice Data Center, Boulder, Colorado

Chi J, Kim H-C, Lee S, Crawford MM (2019) Deep learning based retrieval algorithm for Arctic sea ice concentration from AMSR2 passive microwave and MODIS optical data. Remote Sens Environ 231:111204

Cho K, Naoki K (2015) Advantages of AMSR2 for monitoring sea ice from space. In: Asian Conference on Remote Sensing, Manila, Philippines. 19-23

Du J, Watts JD, Jiang L, Lu H, Cheng X, Duguay C, Farina M, Qiu Y, Kim Y, Kimball JS, Tarolli P (2019) Remote sensing of environmental changes in cold regions: methods, achievements and challenges. Remote Sens 11:1952

Fu S, Goerlandt F, Xi Y (2021) Arctic shipping risk management: a bibliometric analysis and a systematic review of risk influencing factors of navigational accidents. Saf Sci 139:105254

Gavrilov V, Dremliuga R, Nurimbetov R (2019) Article 234 of the 1982 United Nations Convention on the law of the sea and reduction of ice cover in the Arctic Ocean. Mar Policy 106:103518

Giguère M-A, Comtois C, Slack B (2017) Constraints on Canadian Arctic maritime connections, Case Studies on Transport Policy 5: 355-366

Guerreiro K, Fleury S, Zakharova E, Rémy F, Kouraev A (2016) Potential for estimation of snow depth on Arctic sea ice from CryoSat-2 and SARAL/AltiKa missions. Remote Sens Environ 186:339-349

Howell SEL, Komarov AS, Dabboor M, Montpetit B, Brady M, Scharien RK, Mahmud MS, Nandan V, Geldsetzer T, Yackel JJ (2018) Comparing L- and C-band synthetic aperture radar estimates of sea ice motion over different ice regimes. Remote Sens Environ 204:380-391

Jing D, Dai L, Hu H, Ding W, Wang Y, Zhou X (2021) CO2 emission projection for Arctic shipping: a system dynamics approach. Ocean Coast Manag 205:105531

Johansson M, Brekke C, Spreen G, King JA (2018) X-, C-, and L-band SAR signatures of newly formed sea ice in Arctic leads during winter and spring. Remote Sens Environ 204:162-180
Kang D, Im J, Lee M, Quackenbush LJ (2014) The MODIS ice surface temperature product as an indicator of sea ice minimum over the Arctic Ocean. Remote Sens Environ 152:99-108

Kwok R (2014) Declassified high-resolution visible imagery for Arctic sea ice investigations: an overview. Remote Sens Environ 142:44 56

Langehaug HR, Geyer F, Smedsrud LH, Gao Y (2013) Arctic sea ice decline and ice export in the CMIP5 historical simulations. Ocean Model 71:114-126

Lawrence IR, Armitage TWK, Tsamados MC, Stroeve JC, Dinardo S, Ridout AL, Muir A, Tilling RL (2021) Andrew Shepherd, Extending the Arctic sea ice freeboard and sea level record with the Sentinel-3 radar altimeters. Adv Space Res 711-723. in press

Lei R, Gui D, Heil P, Hutchings JK, Ding M (2020) Comparisons of sea ice motion and deformation, and their responses to ice conditions and cyclonic activity in the western Arctic Ocean between two summers. Cold Reg Sci Technol 170:102925

Lindsay R, Schweiger A (2015) Arctic sea ice thickness loss determined using subsurface, aircraft, and satellite observations. Cryosphere 9: 269-283

Lu P, Leppäranta M, Cheng B, Li Z (2016) Influence of melt-pond depth and ice thickness on Arctic sea-ice albedo and light transmittance. Cold Reg Sci Technol 124:1-10

Lu X, Hu Y, Liu Z, Rodier S, Vaughan M, Lucker P, Trepte C, Pelon J (2017) Observations of Arctic snow and sea ice cover from CALIOP lidar measurements. Remote Sens Environ 194:248-263

Mahmud MS, Howell SEL, Geldsetzer T, Yackel J (2016) Detection of melt onset over the northern Canadian Arctic Archipelago sea ice from RADARSAT, 1997-2014. Remote Sens Environ 178:59-69

Mortin J, Howell SEL, Wang L, Derksen C, Svensson G, Graversen RG, Schrøder TM (2014) Extending the QuikSCAT record of seasonal melt-freeze transitions over Arctic sea ice using ASCAT. Remote Sens Environ 141:214-230

Østreng W (2015) Science, geopolitics and culture in the polar region: norden beyond borders. Scandia 81:135-137

Stroeve JC, Markus T, Boisvert L, Miller J, Barrett A (2014) Changes in Arctic melt season and implications for sea ice loss. Geophys Res Lett 41:1,216-1,225

Tilling RL, Ridout A, Shepherd A (2018) Estimating Arctic sea ice thickness and volume using CryoSat-2 radar altimeter data. Adv Space Res 62:1203-1225

Wang M, Yang Q, Overland JE, Stabeno P (2018a) Sea-ice cover timing in the Pacific Arctic: The present and projections to mid-century by selected CMIP5 models. Deep-Sea Res II 152:22-34

Wang Q, Li Z, Lei R, Lu P, Han H (2018b) Estimation of the uniaxial compressive strength of Arctic sea ice during melt season. Cold Reg Sci Technol 151:9-18

Warren SG, Rigor LG, Untersteiner N, Radionov VF, Bryazgin NN, Aleksandrov YI, Colony R (1999) Snow depth on Arctic sea ice. J Clim 12:1814-1829

Yang Q, Mu L, Wu X, Liu J, Zheng F, Zhang J, Li C (2019) Improving Arctic sea ice seasonal outlook by ensemble prediction using an iceocean model. Atmos Res 227:14-23

Zhang Y, Meng Q, Zhang L (2016) Is the northern sea route attractive to shipping companies? Some insights from recent ship traffic data. Mar Policy 73:53-60

Zhang Z, Huisingh D, Song M (2019) Exploitation of trans-Arctic maritime transportation. J Clean Prod 212:960-973 